\title{
Relações hídricas em cultivares de beterraba em diferentes níveis de salinidade do solo ${ }^{1}$
}

\author{
Alexsandro O. da Silva ${ }^{2}$, Antonio E. Klar' ${ }^{2}$, Ênio F. de F. e Silva ${ }^{3}$, \\ Adriana A. Tanaka ${ }^{2} \&$ Josué F. S. Junior ${ }^{2}$
}

\begin{abstract}
RESUMO
O excesso de sais no solo pode afetar diretamente o desenvolvimento e a produtividade das plantas, motivo pelo qual investigações sob as relações hídricas das culturas em tais condições se fazem necessárias para prevenir ou remediar tal problema. O estudo foi conduzido em casa de vegetação, na Universidade Estadual Paulista no Departamento de Engenharia Rural. O delineamento estatístico adotado foi o de blocos casualizados com 4 repetições, 5 níveis de salinidade no solo $\left(1,0 ; 3,0 ; 6,0 ; 9,0 ; 12,0\right.$ dS m m $^{-1}$, duas cultivares de beterraba (Early Wonder e Itapuã) e dois manejos de fertirrigação totalizando, assim, 80 parcelas experimentais. Foram realizados medidas do teor relativo de água nas folhas, resistência difusa ao vapor de água, transpiração, área foliar e o consumo hídrico da cultura. Houve um decréscimo de acordo com o incremento da salinidade para os parâmetros fisiológicos analisados na cultivar Early Wonder enquanto para a cultivar Itapuã um aumento crescente foi observado até a salinidade de $6 \mathrm{dS} \mathrm{m}^{-1}$. O consumo de água pelas plantas apresentou uma redução para as duas cultivares estudadas.
\end{abstract}

Palavras-chave: Beta vulgaris L., consumo hídrico, ambiente protegido

\section{Water relationships in sugar beet cultivars under different levels of soil salinity}

\begin{abstract}
The excess of salts in the soil can directly affect the development and yield of the plants, therefore, studies on water relationships of crops in such conditions are necessary to prevent or solve the problem. The study was conducted in a greenhouse at Universidade Estadual Paulista, Department of Agricultural Engineering, Botucatu, Brazil. The statistical design used was randomized blocks with four replications, consisting of five levels of soil salinity $\left(1.0,3.0,6.0,9.0,12.0 \mathrm{dS} \mathrm{m}^{-1}\right)$, two cultivars of sugar beet (Early Wonder and Itapuã) and two types of management of fertigation, totaling in all 80 plots. Measurements of water content of the leaves, diffuse resistance to water vapor, transpiration, leaf area and the water consumption of crop were determined. There was a decrease according to increasing salinity for the analysed physiological parameters in the Early Wonder variety while for the Itapuã variety a gradual increase was observed up to a salinity of $6 \mathrm{dS} \mathrm{m} \mathrm{m}^{-1}$. The water consumption by plants showed a reduction with increase of soil salinity for the two varieties.
\end{abstract}

Key words: Beta vulgaris L., water consumption, greenhouse 


\section{INTRODUÇÃO}

O processo de salinização em solos utilizados para a agricultura vem sendo, ao longo dos anos, uma das principais preocupações para o setor agrícola, principalmente nas regiões semiáridas constituindo uma preocupação social, ecológica e ambiental uma vez que milhões de hectares de terra em todo o mundo são afetados por sais e a cada ano cresce a área de solos com baixa produtividade. Segundo Gomes et al. (2005) quase $50 \%$ de toda a área irrigada no mundo se encontram afetados por sais sendo a maioria desses solos localizada em regiões de clima árido e semiárido, onde a evapotranspiração tende a superar as chuvas. Consequentemente não ocorre, neste regime, percolação da água de chuva no perfil do solo não proporcionando a lixiviação dos sais. A salinidade induzida pelo homem é a que traz maiores prejuízos econômicos pois ocorre em áreas nas quais se realizou investimento de capital elevado, tais como sistemas de irrigação e fertilizantes. Tal salinidade induzida está geralmente associada ao manejo inadequado da irrigação e fertirrigação podendo ser causada pela baixa qualidade da água de irrigação quanto também pelo excesso de aplicação de fertilizantes ao solo (Silva et al., 2003; Dias et al., 2005; Soares et al., 2010; Silva et al., 2012).

O processo de salinização em solos em condições de ambiente protegido está diretamente relacionado ao acúmulo de sais em excesso na solução do solo. Segundo Silva et al. (2000) existem duas causas que proporcionam o acúmulo de sais nos solos em casas de vegetação, em que a primeira seria a qualidade da água de irrigação e a segunda seria as quantidades superiores de fertilizantes utilizadas para a nutrição das plantas, problema este muito comum entre os produtores de flores e hortaliças. Diversas pesquisas vêm sendo realizadas visando ao controle da salinidade em casa de vegetação (Silva et al., 2003; Eloi et al. 2011; Medeiros et al., 2012) porém nenhuma delas recomenda uma cultura para o desenvolvimento em tal ambiente salino e que possa ser utilizada em conjunto com o monitoramento da salinidade do solo gerando renda para o produtor rural, enquanto os níveis de sais estão impróprios para o cultivo de plantas sensíveis à salinidade.

Utilizada em diversas regiões semiáridas do mundo, a beterraba (Beta vulgaris L.) é uma opção para produção em condições de solos salinos (Katerji et al., 1997), visto que, além de se destacar por sua composição nutricional, sobretudo em açúcares e pela forma de consumo da raiz tuberosa (Aquino et al., 2006) ela se apresenta como uma das hortaliças tolerantes a elevados teores de sais. Segundo Ayers \& Westcot (1991) a beterraba apresenta valores de salinidade limiar (CE) de $7,0 \mathrm{dS} \mathrm{m}^{-1}$, tornando-se mais tolerável ao excesso de sais em estágios avançados de crescimento; por esta razão a utilização desta cultura pode servir como alternativa de renda ao produtor rural com problemas de salinidade em casas de vegetação.

Apesar de sua importância econômica existem poucos trabalhos que estudam o efeito da salinidade sobre esta cultura particularmente se observando as relações hídricas da beterraba sob estresse salino e seu potencial para cultivo em estufas agrícolas afetadas pelo excesso de sais devido ao manejo incorreto da fertirrigação. O objetivo deste trabalho foi estudar o efeito do estresse salino sobre as relações hídricas em duas cultivares de beterraba em condições de ambiente protegido.

\section{Material e Métodos}

O estudo foi conduzido em uma casa de vegetação na Universidade Estadual Paulista, campus de Botucatu, no Departamento de Engenharia Rural no período de novembro de 2011 a janeiro de 2012. Foram utilizadas mudas de beterraba produzidas em bandejas de 128 células e conduzidas até os 25 dias após semeadura, as quais foram transferidas para vasos plásticos com capacidade de $15 \mathrm{~L}$, preenchidos com Latossolo Vermelho com textura argilosa (EMBRAPA, 1997).

$\mathrm{O}$ delineamento estatístico adotado foi o de blocos casualizados, com 4 repetições, com 5 níveis de salinidade no extrato de saturação do solo $\left(1,0 ; 3,0 ; 6,0 ; 9,0 ; 12,0 \mathrm{dS} \mathrm{m}^{-1}\right)$, duas cultivares de beterraba (Early Wonder e Itapuã) e dois manejos de fertirrigação estudados: tradicional, com manejo pré-estabelecido com base na marcha de absorção de nutrientes pela cultura e o controlado, com base na concentração de íons na solução do solo totalizando, assim, 80 parcelas experimentais.

A salinização do solo foi realizada em vasos de $15 \mathrm{~L}$, em cuja base se encontrava uma camada de envelope de $2 \mathrm{~cm}$ (manta síntetica + brita) elevando a umidade à sua máxima capacidade de retenção nos quais foram adicionados os sais fertilizantes, diluídos na água obtendo-se, então, a salinização do solo com valores de condutividade elétrica do extrato de saturação almejados. A proporção de sais e os tipos de sais aplicados foram baseados nas recomendações de Furlani (1998) para soluções nutritivas em hortaliças; as quantidades de sais adicionados foram estimadas pela Eq. 1, apresentada por Richards (1954):

$$
\text { Qs }=\text { CEes.640.Vs }
$$

em que:

QS - quantidade de sais aplicada por vaso, $\mathrm{mg}$

Vs - volume de água presente no solo quando este estiver saturado por vaso, $\mathrm{L}$

CEes - condutividade elétrica almejada no extrato de saturação, dS m ${ }^{-1}$

Adotou-se o sistema de irrigação por gotejamento provido por um sistema de injeção de fertilizantes do tipo Venturi para se realizar os eventos de fertirrigação. O manejo da irrigação foi feito através de tensímetros de punção monitorados diariamente, com base na curva característica de retenção de água no solo (Figura 1).

O consumo de água pelas plantas foi determinado por intermédio do balanço hídrico conforme descrito por Silva et al. (2005). O momento do evento de irrigação foi dado quando a média das leituras dos tensiômetros dos vasos atingia $25 \mathrm{kPa}$ sendo a quantidade de água aplicada suficiente para elevar a umidade até a capacidade de campo conforme Eq. 2.

$$
\mathrm{LLI}=\left(\frac{\mathrm{U}_{\mathrm{cc}}-\mathrm{U}_{\text {atual }}}{10}\right) \cdot d g \cdot Z \cdot P A M
$$

em que:

LLI - lâmina líquida de irrigação, mm

$\mathrm{U}_{\mathrm{cc}}$ - umidade na capacidade de campo, $\mathrm{g} \mathrm{g}^{-1}$ 


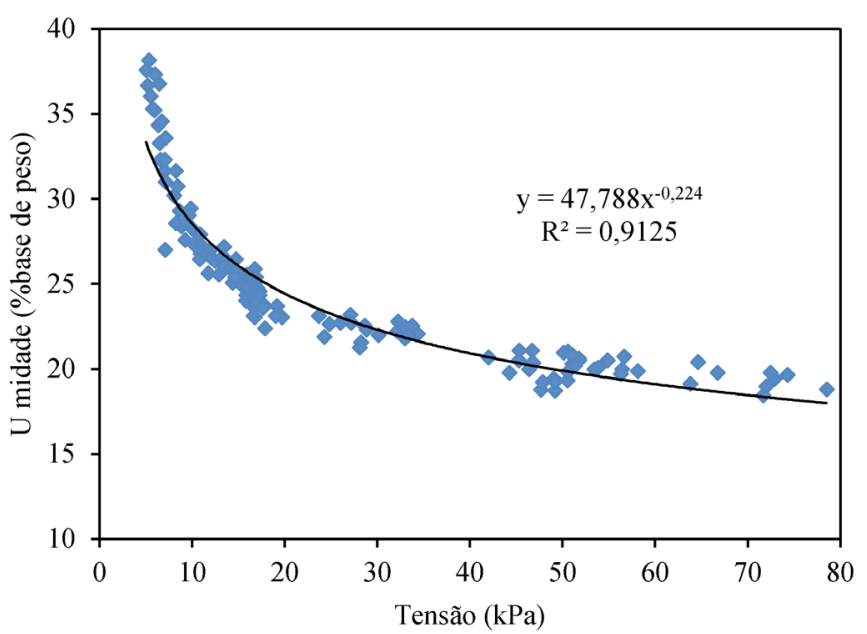

Figura 1. Curva característica de retenção de água no solo

$\mathrm{U}_{\text {atual }}$ - umidade atual no solo, $\mathrm{g} \mathrm{g}^{-1}$

dg - densidade do solo, $\mathrm{g} \mathrm{cm}^{-3}$

$\mathrm{Z} \quad$ - profundidade do sistema radicular, $\mathrm{cm}$

PAM - porcentagem de área molhada, \%

Foram realizadas, semanalmente, medidas do teor relativo de água nas folhas (TRA) através das instruções contidas em Klar (1984) e pela fórmula:

$$
\mathrm{TRA}=\frac{(\mathrm{Pf}-\mathrm{Ps})}{(\mathrm{Pst}-\mathrm{Ps})} \times 100
$$

em que:

TRA - teor relativo de água, \%

Pf - peso fresco do disco foliar, $g$

Ps - peso seco do disco foliar, g

Pst - peso saturado do disco foliar, g

Após transplantio (DAT) foram feitas, todos os dias, leituras das variáveis: resistência difusa ao vapor de água e transpiração com auxílio de um porômetro modelo Licor LI-1600, para determinar o efeito do estresse salino sobre a fisiologia da cultura. Pelo menos três dias da semana leituras foram feitas a cada hora para definir o comportamento fisiológicos da cultura durante o dia. Também foi determinada a área foliar das plantas por meio da metodologia dos discos foliares contida em Marrocos et al. (2010) realizada em três épocas distintas de desenvolvimento aos 20, 40 e 50 DAT.

Durante toda a condução do experimento foram monitoradas, diariamente, as condições ambientais através da leitura da temperatura e umidade relativa do ar com auxílio de um termohigrômetro digital, cujos dados eram coletados diariamente, às $17 \mathrm{~h}$.

Para avaliar os efeitos dos diferentes níveis de salinidade nas variáveis estudadas foi utilizado o método da análise de variância pelo teste $\mathrm{F}$ e se correlacionaram as variáveis em estudo aos níveis de salinidade aplicados. Para a análise dos fatores qualitativos foi aplicado o teste de médias de Tukey a 0,05 de probabilidade. A análise estatística foi obtida através do software R versão 2.8.0 (R Development Core Team, 2008).

\section{Resultados E Discussão}

A temperatura (Figura 2A) dentro do ambiente protegido apresentou média de $26{ }^{\circ} \mathrm{C}$ durante todo o experimento. As temperaturas máximas atingiram em torno de $35^{\circ} \mathrm{C}$ com o maior valor registrado aos 26 DAT atingido valores acima de $50{ }^{\circ} \mathrm{C}$. A temperatura mínima média durante o experimento foi de $16{ }^{\circ} \mathrm{C}$ com o menor valor registrado entre 12 e $14{ }^{\circ} \mathrm{C}$ aos 6 e 7 DAT. A umidade relativa média (Figura $2 \mathrm{~B}$ ) apresentou valor de $60 \%$ durante todo o experimento com a média das máximas de 80 e mínima de $21 \%$.

Na Tabela 1 se apresenta um resumo da análise de variância para as variáveis estudadas. O fator cultivar apresentou diferença significativa apenas para os valores do consumo hídrico das plantas. Verificou-se que todas as variáveis diferiram significativamente em função do fator salinidade do solo enquanto o fator manejo da fertirrigação interferiu nas variáveis transpiração $(\mathrm{T})$, resistência ao vapor de águas nas folhas (Rs) e área foliar (AF). A interação entre salinidade e manejo apresentou significância entre as variáveis teor relativo de água (TRA) e T. As interações entre os fatores salinidade e cultivar e cultivar e manejo da fertirrigação não apresentaram efeito significativo para as variáveis estudadas.
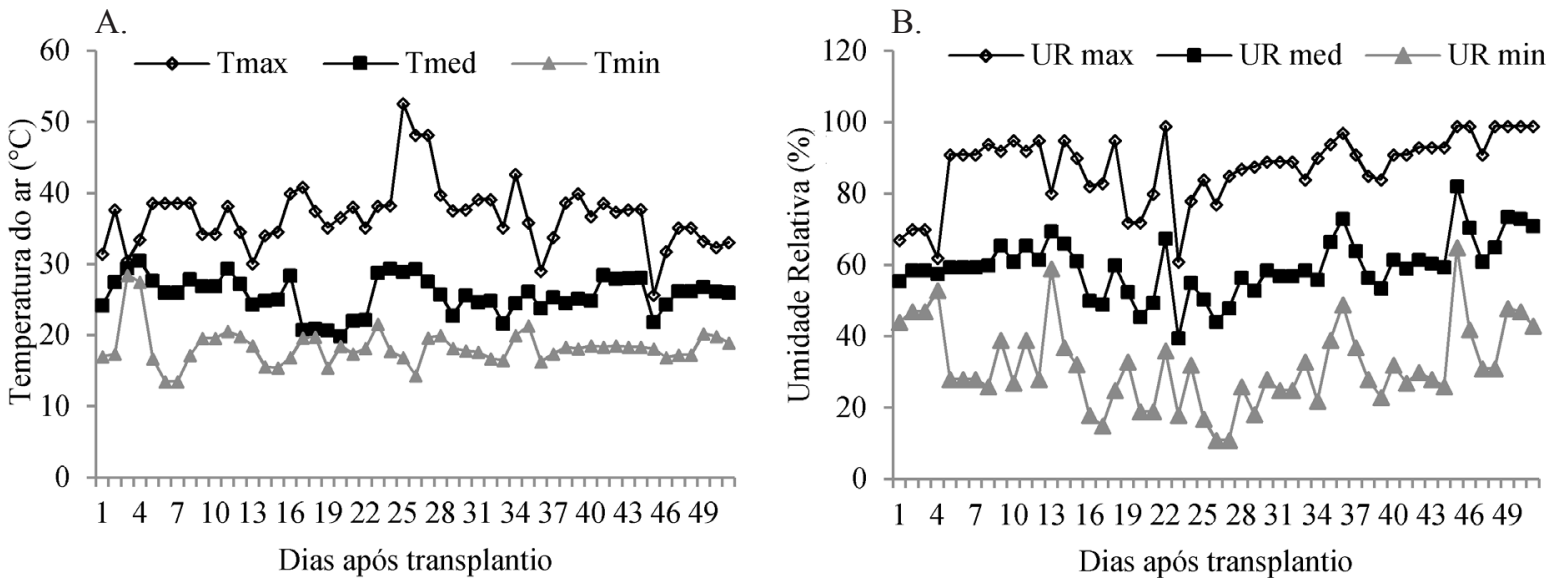

Figura 2. Temperatura do ar máxima, média e mínima (A) e umidade relativa máxima, média e mínima (B) durante o ciclo de cultivo da beterraba 
Tabela 1. Resumo da análise de variância para $O$ consumo hídrico $(\mathrm{CH})$, teor relativo de água (TRA), resistência difusiva ao vapor (RS), transpiração (T) e área foliar (AF) em função dos níveis de salinidade, cultivar e manejo

\begin{tabular}{|c|c|c|c|c|c|}
\hline \multirow{2}{*}{$\begin{array}{l}\text { Causa da } \\
\text { variação }\end{array}$} & \multicolumn{5}{|c|}{ Teste F } \\
\hline & $\mathrm{CH}$ & TRA & RS & $\mathbf{T}$ & AF \\
\hline \multicolumn{6}{|l|}{ Tratamentos } \\
\hline Blocos & $0,991^{\mathrm{ns}}$ & $1,048^{\text {ns }}$ & $1,025^{\mathrm{ns}}$ & $3,268 * \star$ & $0,613^{\text {ns }}$ \\
\hline Cultivar (C) & $42,988 * *$ & $0,073^{\text {ns }}$ & $0,559^{\text {ns }}$ & $0,108^{\text {ns }}$ & $0,148^{\text {ns }}$ \\
\hline Manejo (M) & $128,253^{\star \star}$ & $0,933^{\text {ns }}$ & $3,493^{\star \star}$ & $18,210 * \star$ & $52,955^{\star \star}$ \\
\hline Salinidade (S) & $128,717^{\star \star}$ & $11,399 * \star$ & $27,714^{\star \star}$ & $15,732^{\star \star}$ & $1,919^{\text {ns }}$ \\
\hline$S \times C$ & $1,319^{\text {ns }}$ & $0,463^{\text {ns }}$ & $1,170^{\text {ns }}$ & $1,185^{\mathrm{ns}}$ & $0,919^{\text {ns }}$ \\
\hline$S \times M$ & $112,488 * \star$ & $4,534^{\star \star}$ & $1,834^{\mathrm{ns}}$ & $16,055^{\star \star}$ & $1,931^{\mathrm{ns}}$ \\
\hline$C \times M$ & $2,032^{\mathrm{ns}}$ & $0,996^{\mathrm{ns}}$ & $0,140^{\mathrm{ns}}$ & $0,970^{\text {ns }}$ & $0,368^{\text {ns }}$ \\
\hline$S \times C \times M$ & $1,441^{\text {ns }}$ & $0,685^{\text {ns }}$ & $0,576^{\text {ns }}$ & $1,509^{\text {ns }}$ & $1,126^{\text {ns }}$ \\
\hline C.V. (\%) & 6,35 & 12,30 & 19,61 & 11,80 & 7,98 \\
\hline
\end{tabular}

$\mathrm{Na}$ Tabela 2 se encontra apresentado o teste de Tukey para comparação das médias das variáveis estudadas para o fator cultivar. As diferenças só foram encontradas para o consumo hídrico das plantas sendo que a cultivar Early Wonder apresentou um consumo maior de água durante todo o ciclo. Segundo Filgueira (2008) esta cultivar é adaptada a períodos mais frios, portanto, talvez temperaturas mais elevadas registradas durante o ciclo de cultivo possam ter contribuído para um consumo maior da planta quando comparado com a cultivar Itapuã que é uma variedade adaptada às condições climáticas locais.

Tabela 2. Consumo hídrico $(\mathrm{CH})$, teor relativo de água (TRA), resistência difusiva ao vapor de água (Rs), transpiração (T) e área foliar (AF) para o fator cultivar

\begin{tabular}{|c|c|c|c|c|c|}
\hline Cultivar & $\begin{array}{l}\mathrm{CH} \\
\mathrm{mm}\end{array}$ & $\begin{array}{l}\text { TRA } \\
\text { (\%) }\end{array}$ & $\begin{array}{c}\text { Rs } \\
S \mathrm{~cm}^{-1}\end{array}$ & $\begin{array}{c}\mathrm{T} \\
\mathrm{mmol} \mathrm{m}^{2} \mathrm{~s}^{-1}\end{array}$ & $\begin{array}{l}\mathrm{AF} \\
\mathrm{m}^{2}\end{array}$ \\
\hline Early Wo & $71,10 \mathrm{a}^{1}$ & $57,75 \mathrm{a}$ & $3,00 \mathrm{a}$ & $2,90 \mathrm{a}$ & $0,178 \mathrm{a}$ \\
\hline Itapuã & $64,75 \mathrm{~b}$ & $57,60 \mathrm{a}$ & $3,00 \mathrm{a}$ & $2,87 \mathrm{a}$ & $0,183 \mathrm{a}$ \\
\hline D.M.S & 1,93 & 3,16 & 0,26 & 0,15 & 0,930 \\
\hline
\end{tabular}

${ }^{1}$ Médias seguidas de letras iguais não diferem estatisticamente a 0,05 de probabilidade pelo teste de Tukey

De acordo com o teste de Tukey a 0,05 de probabilidade para o fator manejo da fertirrigação (Tabela 3 ) observamse diferenças nas médias das variáveis consumo hídrico, transpiração e área foliar. $\mathrm{O}$ excesso de sais teoricamente provocado pela aplicação exagerada de fertilizantes no manejo tradicional promoveu redução na área foliar e aumento na transpiração das plantas, segundo Chen \& Jiang (2010); os solutos dissolvidos na zona das raízes geram um potencial osmótico mais baixo, o que diminui o potencial total do solo; assim, o desenvolvimento das plantas é prejudicado incluindo $\mathrm{a}$ área foliar sendo necessária uma energia maior por parte da planta (ajuste osmótico) para gerar potenciais mais negativos que o encontrado nos solos para absorção de água. Tais gastos de energia envolvem uma transpiração maior por parte da planta quanto maior é a salinidade do solo.

$\mathrm{Na}$ Tabela 4 se encontram as médias referentes à interação entre os fatores salinidade do solo e manejo de fertirrigação evidenciando diferenças significativas tanto entre os níveis
Tabela 3. Consumo hídrico $(\mathrm{CH})$, teor relativo de água (TRA), resistência difusiva ao vapor de água (Rs), transpiração (T) e área foliar (AF) para o fator manejo da fertirrigação

\begin{tabular}{lccccc}
\hline \multicolumn{1}{c}{ Manejo } & $\begin{array}{c}\mathbf{C H} \\
\mathbf{m m}\end{array}$ & $\begin{array}{c}\text { TRA } \\
\mathbf{( \% )}\end{array}$ & $\begin{array}{c}\text { Rs } \\
\mathbf{s ~ c m}^{-1}\end{array}$ & $\begin{array}{c}\mathbf{T} \\
\mathbf{m m o l} \mathbf{~ m}^{2} \mathbf{~}^{-1}\end{array}$ & $\begin{array}{c}\text { AF } \\
\mathbf{m}^{2}\end{array}$ \\
Tradicional & $73,47 \mathrm{a}^{1}$ & $56,62 \mathrm{a}$ & $2,92 \mathrm{a}$ & $3,05 \mathrm{a}$ & $0,146 \mathrm{a}$ \\
Controlado & $62,45 \mathrm{~b}$ & $58,15 \mathrm{a}$ & $3,17 \mathrm{a}$ & $2,72 \mathrm{~b}$ & $0,215 \mathrm{~b}$ \\
\hline D.M.S. & 1,93 & 3,16 & 0,26 & 0,15 & 0,090 \\
\hline
\end{tabular}

${ }^{1}$ Médias seguidas de letras iguais não diferem estatisticamente a 0,05 de probabilidade pelo teste de Tukey

de salinidade do solo quanto entre os tipos de manejo de fertirrigação para as variáveis $\mathrm{CH}$, TRA e T. O manejo da fertirrigação tradicional apresentou os maiores valores para a variável $\mathrm{CH}$ com o nível de salinidade $\mathrm{S} 12$ sinalizando as menores médias entre os manejos. O manejo por controle apresentou as maiores médias para as variáveis TRA e T com o nível de salinidade S12 indicando as menores médias entre os tratamentos.

Tabela 4. Valores médios das variáveis consumo hídrico - $\mathrm{CH}(\mathrm{mm})$, teor relativo de água - TRA (\%) e transpiração - $\mathrm{T}\left(\mathrm{mmol} \mathrm{m}^{2} \mathrm{~s}^{-1}\right)$ entre os tipos de manejo da fertirrigação e os níveis de salinidade do solo

\begin{tabular}{|c|c|c|c|c|c|c|}
\hline \multirow{2}{*}{$\begin{array}{l}\text { Níveis de } \\
\text { salinidade }\end{array}$} & \multicolumn{2}{|c|}{$\mathrm{CH}$} & \multicolumn{2}{|c|}{ TRA } & \multicolumn{2}{|c|}{$\bar{T}$} \\
\hline & $\mathrm{M} 1^{3}$ & M2 & M1 & M2 & M1 & M2 \\
\hline S1 & $97,25 \mathrm{Aa}^{1}$ & $52,25 \mathrm{BC}$ & $53,37 \mathrm{Bab}$ & $66,87 \mathrm{Aa}$ & $3,00 \mathrm{Ba}$ & $3,50 \mathrm{Aa}$ \\
\hline S3 & $86,00 \mathrm{Ab}$ & $63,75 \mathrm{Bb}$ & $60,25 \mathrm{Aa}$ & $64,25 \mathrm{Aa}$ & $3,12 \mathrm{Aa}$ & $3,00 \mathrm{Ab}$ \\
\hline S6 & $72,62 \mathrm{Bc}$ & $85,62 \mathrm{Aa}$ & $61,87 \mathrm{Aa}$ & $59,25 \mathrm{Aab}$ & $3,00 \mathrm{Aa}$ & $3,00 \mathrm{Ab}$ \\
\hline S9 & $61,00 \mathrm{Ad}$ & $61,25 A b$ & $58,37 \mathrm{Aab}$ & $54,25 \mathrm{Aab}$ & $3,12 \mathrm{Aa}$ & $2,37 \mathrm{Bc}$ \\
\hline $\mathrm{S} 12$ & $50,12 \mathrm{Ae}$ & $49,12 \mathrm{Ac}$ & $49,25 A b$ & $45,75 \mathrm{Ab}$ & $3,00 \mathrm{Aa}$ & $1,75 \mathrm{Bd}$ \\
\hline
\end{tabular}

1Médias seguidas da mesma letra maiúscula nas linhas e minúsculas nas colunas não diferem entre si pelo teste de Tukey a nível de 0,05 de probabilidade

${ }^{2} \mathrm{~S} 1$ a S12 - referem-se às CEes do solo 1, 3, 6, 9 e $12 \mathrm{dS} \mathrm{m}^{-1}$

${ }^{3} \mathrm{M} 1$ e M2 - referem-se ao manejo tradicional e controlado da fertirrigação

De acordo com os níveis de salinidade, o consumo hídrico da planta apresentou uma tendência diferenciada para as cultivares estudadas quando relacionadas com a salinidade do solo. Na cultivar Early Wonder a curva ajustada foi o modelo linear de regressão (Figura 3) para ambos os manejos. Os estudos apresentaram uma redução linear de $4,0356 \mathrm{~L}$ por planta para o manejo tradicional e 4,585 L por planta para o manejo por controle para os valores de consumo hídrico das plantas a cada aumento unitário da salinidade do solo. Silva et al. (2005) observaram, em trabalho semelhante com a cultura do pimentão submetido a um solo salinizado com sais fertilizantes, a redução no consumo hídrico da cultura que também pode ser observada em cultivo sem solo e com águas salinas, como estudado por Silva et al. (2012) com a cultura da rúcula em sistema hidropônico em que os autores observaram redução no consumo hídrico das plantas de acordo com o aumento da salinidade da água aplicada.

Na Figura 4 pode-se observar a análise de regressão na cultivar Early Wonder para as variáveis estudadas. O TRA apresentou um ajuste quadrático para o manejo tradicional da fertirrigação com o valor máximo do TRA na condutividade de $5,632 \mathrm{dS} \mathrm{m}^{-1}$ enquanto para o manejo controlado (Figura 4B) o ajuste foi linear com redução de $2,1673 \%$ do valor de TRA por aumento unitário da salinidade no solo. Ghoulam et al. 
A.

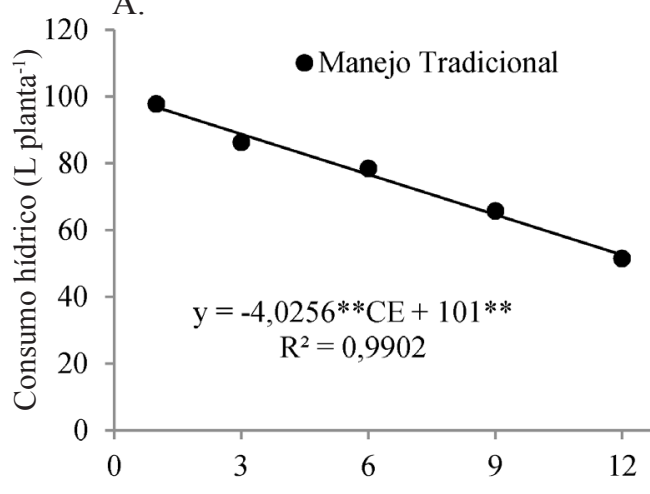

B.

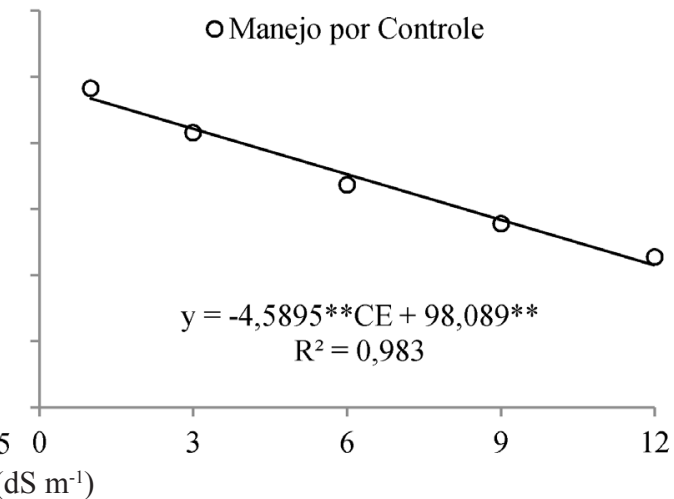

Figura 3. Consumo hídrico acumulado para a cultivar Wonder no manejo tradicional (A) e por controle (B)

(2002) encontraram, em estudos com salinidade em diferentes cultivares de beterraba, uma diferença crescente de acordo com o aumento da salinidade em que a cultura foi submetida ao teor relativo de água nas folhas. Moreno et al. (2001) perceberam, em cultivo de beterraba com água salina, que houve um decréscimo no potencial hídrico das folhas da cultura.

A resistência difusiva ao vapor de água nas folhas (Rs) apresentou diferentes ajustes de conformidade com o manejo estudado. Observam-se ajustes quadráticos com valores máximos observados na condutividade elétrica de 7,18 $\mathrm{dS} \mathrm{m}{ }^{-1}$ no manejo tradicional (Figura 4C) e de 9,07 $\mathrm{dS} \mathrm{m}^{-1}$ para o manejo controlado (Figura 4D). Tal comportamento pode ter sido causado pela adaptação da planta ao meio salino contínuo, principalmente no manejo por controle. A variável transpiração em função da salinidade do solo apresentou ajuste linear quadrático com redução dos valores
A.

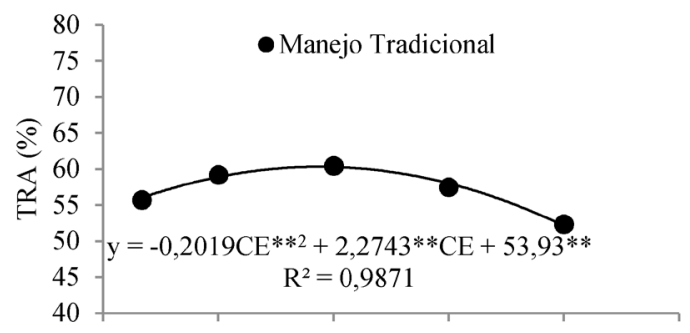

C.

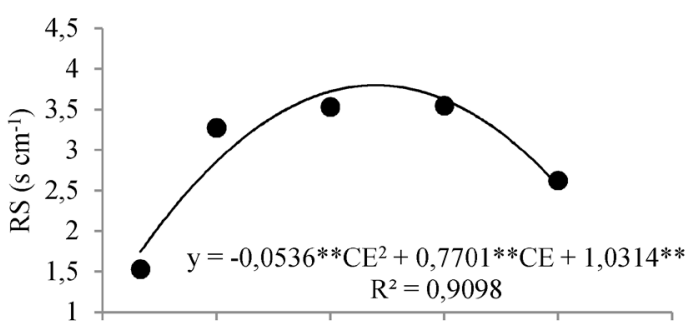

E.

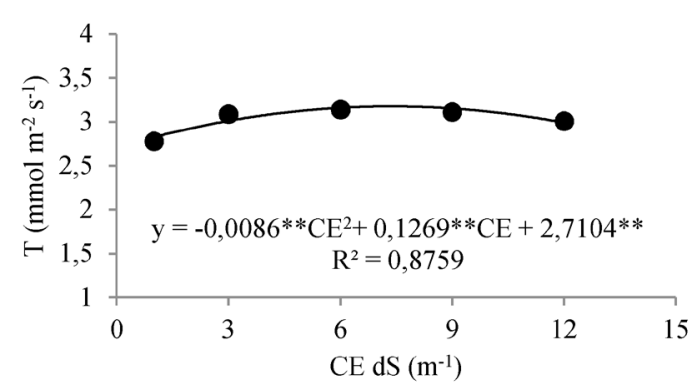

B.

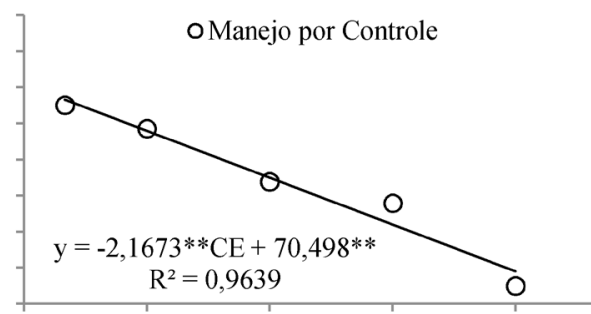

D.

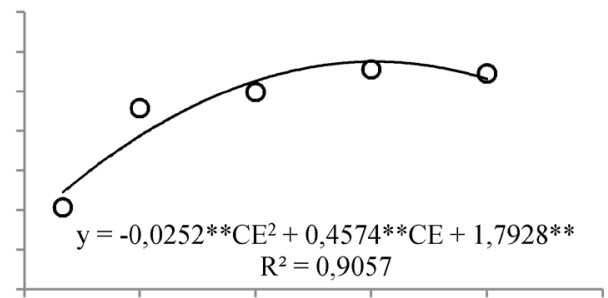

F.

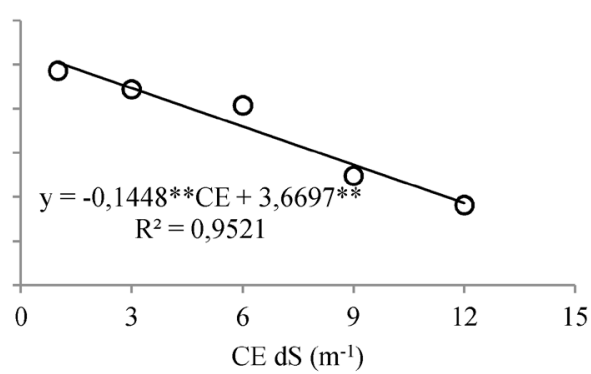

** significativo a 0,01 de probabilidade

Figura 4. Teor relativo de água nas folhas (TRA) para o manejo tradicional (A) e controlado (B); resistência difusiva ao vapor de água (Rs) para o manejo tradicional (C) e controlado (D); transpiração da planta (T) para o manejo tradicional (E) e controlado (F) para a cultivar Early Wonder sob diferentes níveis de salinidade do extrato de saturação do solo (CE) 
na condutividade elétrica de $7,37 \mathrm{dS} \mathrm{m}^{-1}$, conforme o aumento da salinidade do solo para o manejo tradicional (Figura 4E) e redução de 0,1448 nos valores de transpiração de acordo com o aumento unitário da condutividade elétrica para o manejo controlado (Figura 4F). Távora et al. (2001) perceberam, relacionando dados fisiológicos ao estresse salino, um decréscimo na transpiração das plantas de goiabeira nos diversos períodos analisados o que prova a influência da salinidade neste parâmetro.

Os valores médios das variáveis TRA, Rs e T ao longo do dia para a cultivar Early Wonder estão apresentados na Figura 5. Verifica-se, para o TRA, que os maiores valores foram observados às 8 e $16 \mathrm{~h}$ período este que coincide com as menores temperaturas registradas no ambiente protegido. Os maiores valores encontrados para Rs foram registrados entre $12 \mathrm{e} 14 \mathrm{~h}$ do dia com pico máximo às $14 \mathrm{~h}$, com temperaturas acima de $28{ }^{\circ} \mathrm{C}$; o mesmo pode ser verificado para $\mathrm{T}$; não houve uma variação significativa nas características avaliadas entre os níveis de salinidade em que ambas as cultivares foram submetidas ao longo do dia. Katerji et al. (1997) observaram, estudando o efeito da salinidade do solo no cultivo da beterraba açucareira o decréscimo do teor relativo de água na cultura de acordo com o crescimento da cultura.

A.

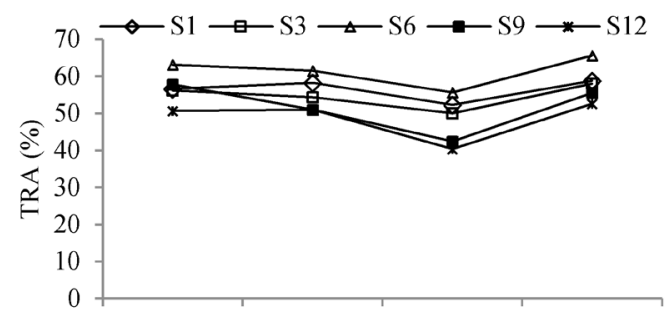

C.

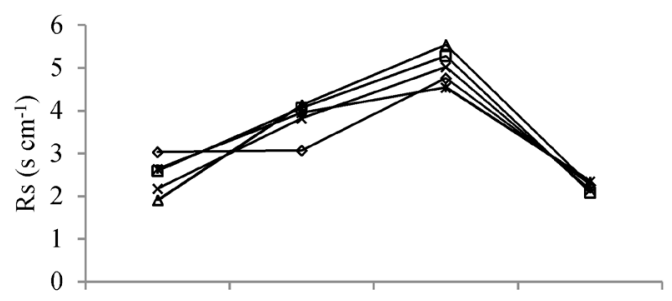

E.

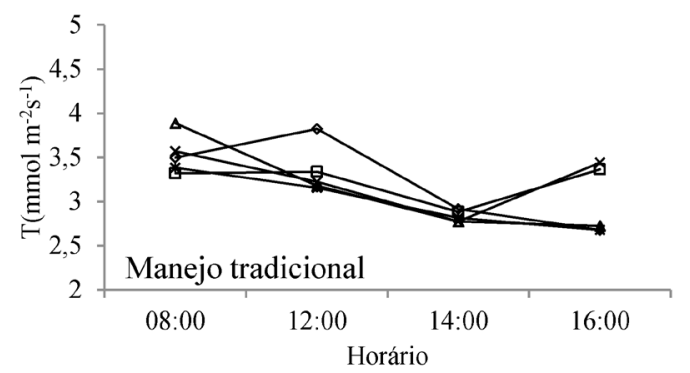

Para a cultivar Itapuã ambos os manejos da fertirrigação apresentaram semelhanças com relação ao consumo hídrico (Figura 6). É provável que tenha ocorrido um ajustamento osmótico provocado pelo incremento da salinidade do solo encontrando um ponto ótimo no tratamento S6. Tal hipótese concorda com os estudos de Silva et al. (2005) com a evapotranspiração da cultura do pimentão que apontam uma interferência no potencial osmótico e no consumo hídrico das plantas devido ao aumento da salinidade do solo. Alguns autores, como Sousa et al. (2011) afirmam que o ajustamento osmótico é o principal responsável pelo aumento do consumo e declínio nos tratamentos de maiores concentrações de sais.

Os diagramas de dispersão para TRA, RS e T nos diferentes manejos de fertirrigação para a cultivar Itapuã se apresentam na Figura 7. Para o manejo tradicional (Figura 7A) os valores de TRA apresentaram um ponto ótimo na condutividade elétrica de 5,95 $\mathrm{dS} \mathrm{m}^{-1}$ enquanto para o manejo por controle (Figura 7B) o ajuste foi linear com decréscimo de 1,5903, de acordo com o aumento unitário da salinidade do solo. A resistência difusiva ao vapor de água (Rs) para ambos os manejos apresentou ajuste polinomial quadrático com os maiores valores encontrados na salinidade inicial de 7,18 dS m${ }^{-1}$ (Figura 7C) para o manejo tradicional e 9,07 $\mathrm{dS} \mathrm{m}^{-1}$ para o manejo por controle (Figura

B.

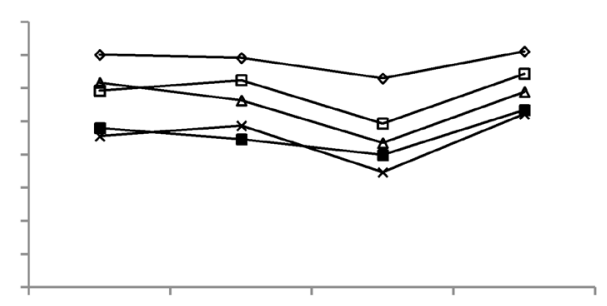

D.

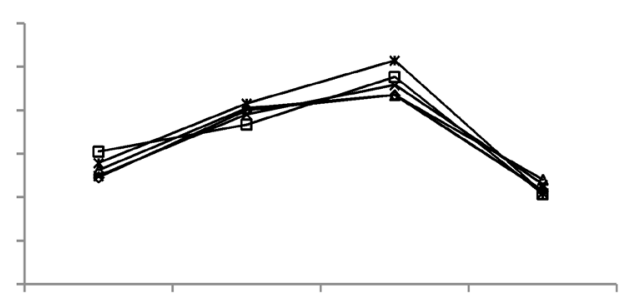

F.

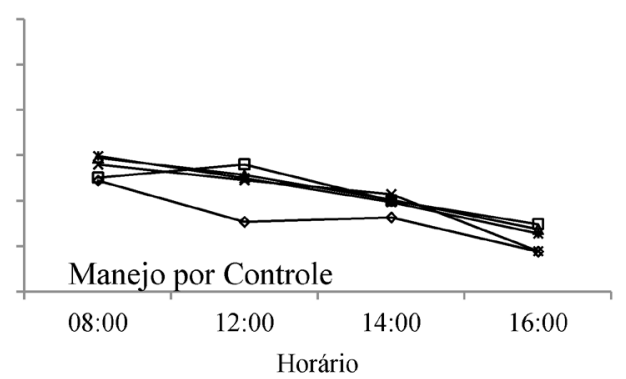

Figura 5. Valores médios do teor relativo de água na folha (TRA) para o manejo tradicional (A) e controlado (B), resistência difusiva ao vapor (RS) para o manejo tradicional $(C)$ e controlado (D), transpiração (T) para o manejo tradicional (E) e controlado (F) na cultivar Early Wonder ao longo do dia, sob diferentes níveis de salinidade do solo $\left(S_{1}-1,0, S_{3}-3,0, S_{6}-6,0, S_{9}-9,0\right.$ e $\left.S_{12}-12,0 d S m^{-1}\right)$ 


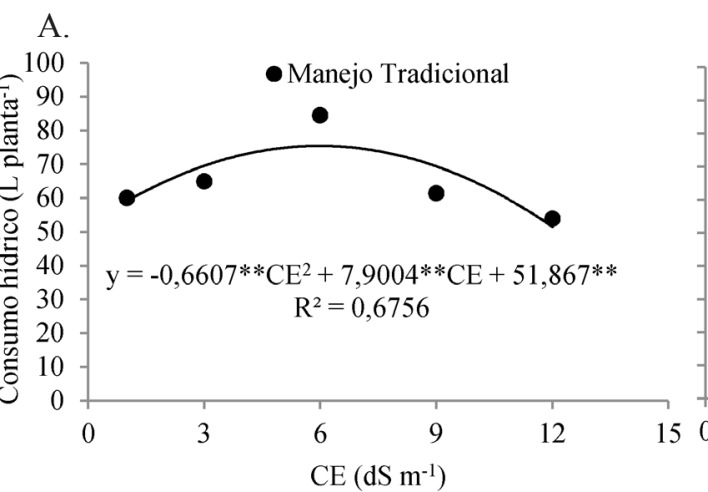

B.

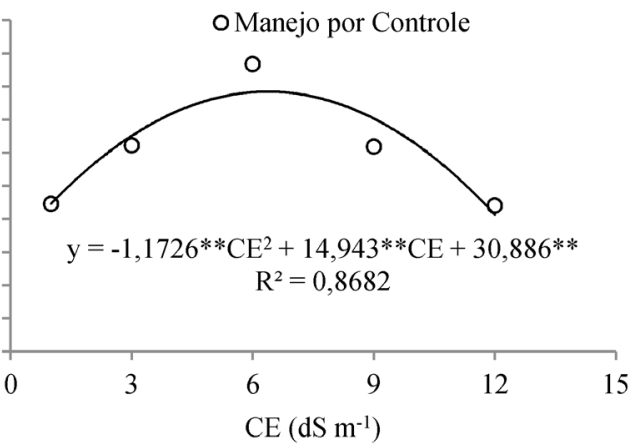

Figura 6. Consumo hídrico acumulado para a cultivar Itapuã: manejo tradicional (A) e manejo por controle (B) sob diferentes níveis de salinidade do extrato de saturação do solo (CE)

A.

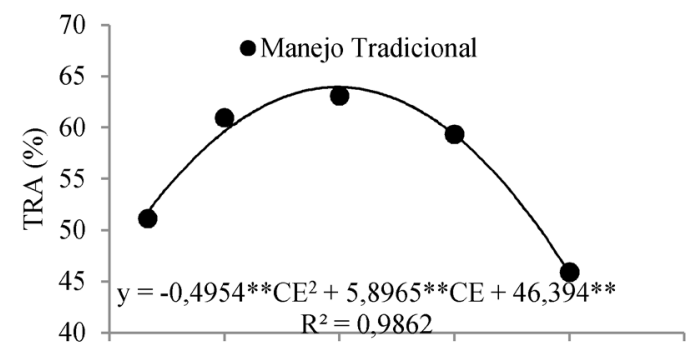

C.

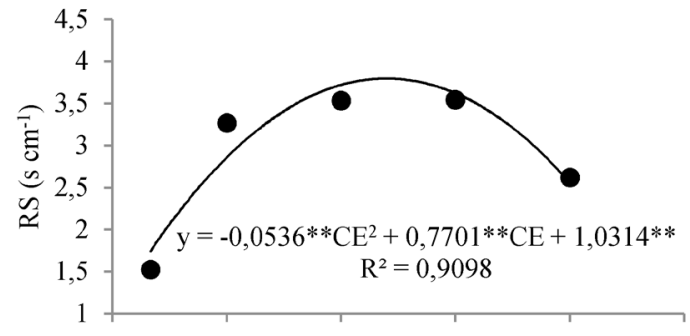

E.

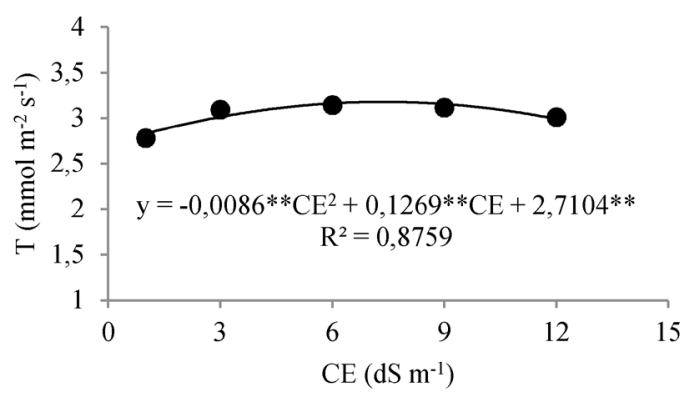

B.

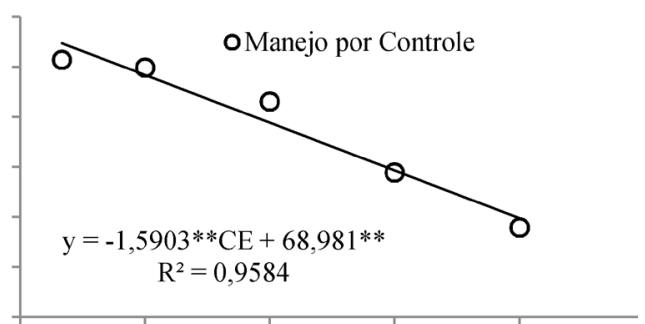

D.

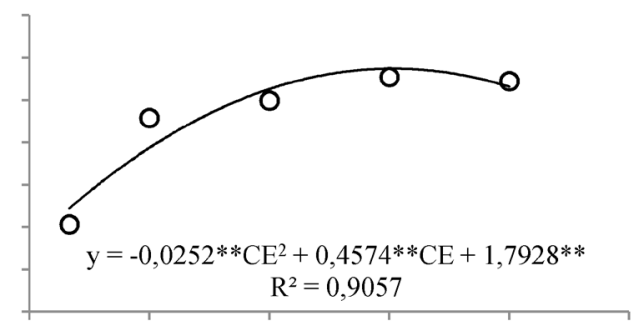

F.

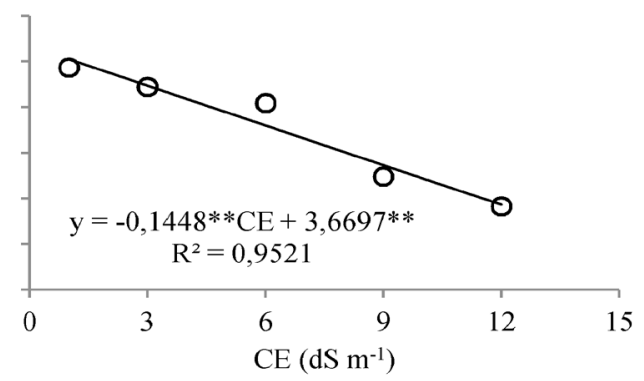

** significativo a 0,01 de probabilidade

Figura 7. Teor relativo de água nas folhas (TRA) para o manejo tradicional (A) e controlado (B); resistência difusiva ao vapor de água (Rs) para o manejo tradicional (C) e controlado (D); transpiração da planta (T) para o manejo tradicional (E) e controlado (F) para cultivar Itapuã sob diferentes níveis de salinidade do extrato de saturação do solo (CE)

7D). Tais valores apresentam comportamento diferente dos apresentados por Katerji et al. (1997) que, trabalhando com beterraba açucareira sob condições de estresse salino $(\mathrm{NaCl})$ observaram que o potencial hídrico da folha, tal como as demais variáveis hídricas decresceu com a salinidade do solo quando cultivada em 0 a $200 \mathrm{mmol} \mathrm{L}^{-1}$ de $\mathrm{NaCl}$, respectivamente.

O diagrama de dispersão para a transpiração nas folhas teve comportamento diferente entre os manejos da fertirrigação estudados. Para o manejo tradicional (Figura 7E) o maior valor foi encontrado na salinidade de 7,37 $\mathrm{dS} \mathrm{m}^{-1}$ enquanto para o manejo por controle (Figura 7F) ocorreu decréscimo de 0,1448 nos valores da transpiração de acordo com o aumento unitário da salinidade do solo.

Tais resultados apresentados pelo manejo tradicional se aplicam ao acúmulo de sais durante todo o ciclo da cultura devido às excessivas aplicações de fertirrigação por parte dos 
A.

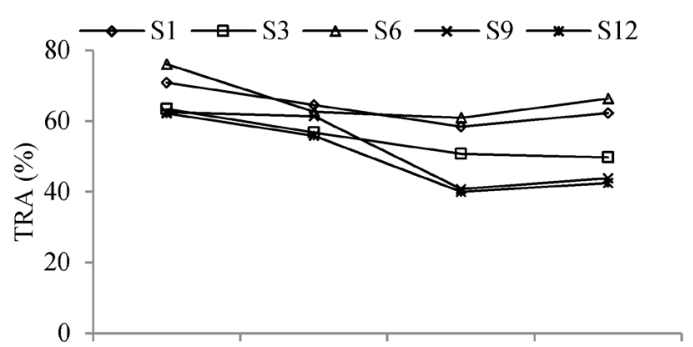

C.

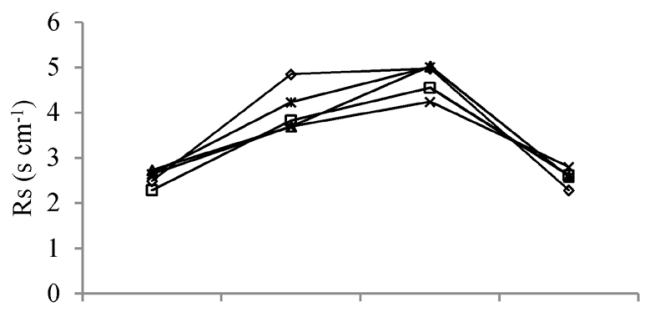

E.

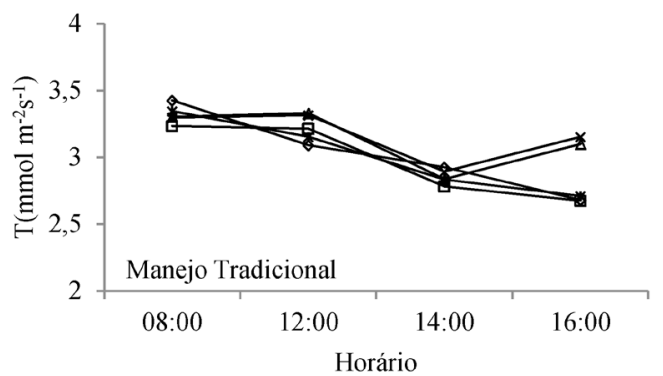

B.

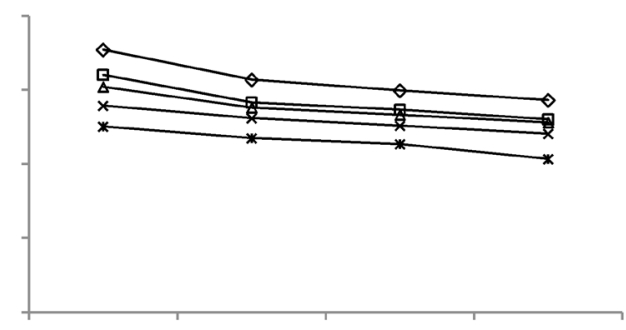

D.

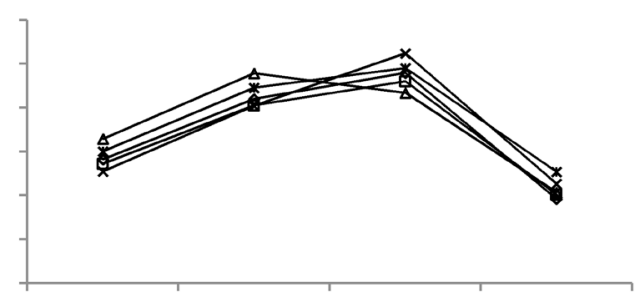

F.

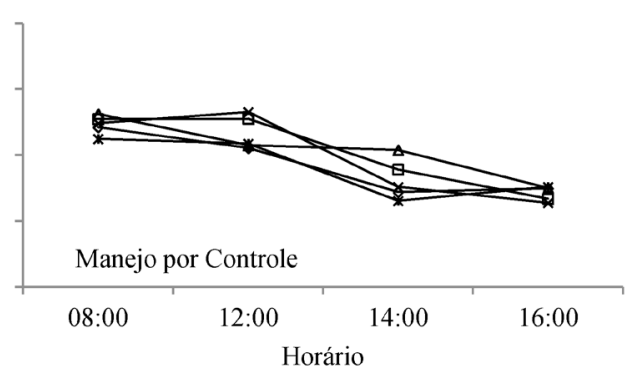

Figura 8. Valores médios do teor relativo de água (TRA) para o manejo tradicional (A) e manejo por controle (B), resistência difusiva ao vapor (RS) para o manejo tradicional (C) e controlado (D), transpiração (T) para o manejo tradicional $(\mathrm{E})$ e controlado $(\mathrm{F})$ para a cultivar Itapuã ao longo do dia, sob diferentes níveis de salinidade do solo $\left(S_{1}-1,0, S_{3}-3,0, S_{6}-6,0, S_{9}-9,0\right.$ e $\left.S_{12}-12,0 d S m^{-1}\right)$

tratamentos apresentando, deste modo, menores valores das variáveis estudadas quando comparadas com o tratamento por controle. Chen \& Jiang (2010) afirmam, falando sobre o efeito dos sais nas plantas, que o efeito dos sais provoca redução da parte área de certas plantas em razão delas não apresentarem um ajuste osmótico como mecanismo de adaptabilidade ao excesso de sais na solução do solo.

Os valores das variáveis TRA, Rs e T para cultivar Itapuã ao longo do dia, se encontram na Figura 8; nota-se que não houve diferença entre os manejos da fertirrigação apresentados com relação às variáveis estudadas. Katerji et al. (1997) em estudo com salinidade em solos salinos observaram que houve um decréscimo na condutância estomática e na transpiração das plantas de acordo com o aumento dos níveis de sais estudados sinalizando, assim, a adaptação fisiológica da cultura à salinidade. Segundo Chen \& Jiang (2010) técnicas devem surgir com o avanço das pesquisas para que as novas cultivares suportem o estresse causado pelo excesso de sais no solo.

\section{CONCLUSÕES}

1. O consumo de água pelas plantas apresentou uma redução de acordo com o incremento da salinidade para a cultivar Early
Wonder. A cultivar Itapuã apresentou aumento do consumo hídrico até a salinidade limiar de $6 \mathrm{dS} \mathrm{m}^{-1}$ para ambos os manejos de fertirrigação e diminuição dos valores estudados a partir da salinidade limiar de $9 \mathrm{dS} \mathrm{m}^{-1}$.

2. As plantas de beterraba responderam de maneira significativa aos parâmetros analisados em salinidade limiar próxima a $6 \mathrm{dS} \mathrm{m}^{-1}$. O incremento da salinidade do solo através do manejo tradicional provocou uma redução na capacidade de absorção de águas pelas plantas ocasionando redução nas variáveis analisadas.

3. As plantas de beterraba apresentaram alterações no mecanismo fisiológico em função das condições hídroclimáticas ocorrentes ao longo do dia. O horário entre 12 e 14 h é o mais indicado para avaliações de disponibilidade hídrica para a cultura por apresentar variações mínimas entre os valores estudados.

\section{Agradecimentos}

Os autores agradecem à Coordenação de Aperfeiçoamento de Pessoal de Nível Superior (CAPES) pela concessão da bolsa de estudo e ao CNPq pelas bolsas de produtividade em pesquisa. 


\section{Literatura Citada}

Aquino, L. A.; Puiatti, M.; Pereira, P. R. G.; Pereira, F. H. F.; Ladeira, I. R.; Castro, M. R. S. Produtividade, qualidade e estado nutricional da beterraba de mesa em função de doses de nitrogênio. Horticultura Brasileira, v.24, p.199203, 2006.

Ayers, R. S.; Westcot, D. W. Qualidade de água na agricultura. Campina Grande: UFPB, 1991. 218p. Estudos FAO, Irrigação e drenagem, 29

Chen, H.; Jiang, J. Osmotic adjustment and plant adaptation to environmental changes related to drought and salinity. Environmental Reviews, v.18, p.309-319, 2010.

Dias, N. S.; Duarte, S. N.; Gheyi, H. R.; Medeiros, J. F.; Soares, T. M. Manejo da Fertirrigação e controle da salinidade do solo sob ambiente protegido, utilizando-se extratores de solução do solo. Revista Brasileira de Engenharia Agrícola e Ambiental, v.9, p.496-504, 2005.

Eloi, W. M.; Duarte, S. N.; Soares, T. M.; Silva, E. F. F.; Miranda, J. H. Rendimento do tomateiro em resposta à salinização ocasionada pela fertigação em ambiente protegido. Revista Brasileira de Engenharia Agrícola e Ambiental, v.15, p.471-476, 2011.

EMBRAPA - Empresa Brasileira de Pesquisa Agropecuária. Serviço nacional de levantamento e conservação do solo. Manual de métodos de análises de solo. 2.ed. Rio de Janeiro: EMBRAPA, 1997. 212p.

Filgueira, F. A. R. Novo manual de olericultura: Agrotecnologia moderna na produção e comercialização de hortaliças. Viçosa: UFV, 2008. 412p.

Furlani, P. R. Instruções para o cultivo de hortaliças de folhas pela técnica de Hidroponia NFT. In: Van Raij, B.; Cantarella, H.; Quaggio, J. A.; Furlani, A. M. C. Recomendações de adubação e calagem para o Estado de São Paulo, 3.ed., Campinas: Instituto Agronômico, 1998. 285p. Boletim técnico, 100.

Ghoulam, C.; Foursy, A.; Fares, K. Effects of salt stress on growth, inorganic ions and proline accumulation in relation to osmotic adjustment in five sugar beet cultivars. Environmental and Experimental Botany, v.47, p.39-50, 2002.

Gomes, E. W. F.; Willadino, L.; Martins, L. S. S.; Camara, T. $R$. Variedades de bananeira tratadas com água salinizada em fase inicial de crescimento. Revista Brasileira de Engenharia Agrícola e Ambiental, v.9, p.31-36, 2005.

Katerji, N.; Hoom, J. W.; Hamdy, A.; Mastrorilli, M.; Karzel, E. M. Osmotic adjustment of sugar beets in response to soil salinity and its influence on stomatal conductance, growth and yield. Agricultural Water Management, v.34, p.57-69, 1997.
Klar, A. E. Aágua no sistema solo-planta-atmosfera. São Paulo: Nobel, 1984. 408p.

Marrocos, S. T. P.; Dantas, M. S. M.; Dombroski, J. L. D.; Lucena, R. R. M.; Batista, T. M. de V. Análise comparativa de métodos de estimativa de área foliar em beterraba. Revista Caatinga, v.5, p.140-146, 2010.

Medeiros, P. R. F.; Duarte, S. N., Silva, E. F. F. Eficiência do uso da água e de fertilizantes no manejo de fertirrigação no cultivo do tomateiro sob condições de salinidade do solo. Revista Brasileira de Ciências Agrárias, v.7, p.344-351, 2012.

Moreno, F.; Cabrera, F.; Fernández-Boy, E.; Girón, I. F.; Fernández, J. E.; Bellido, B. Irrigation with saline water in the reclaimed marsh soils of south-west Spain: Impact on soil properties and cotton and sugar beet crops. Agricultural Water Management, v.48, p.133-150, 2001.

R Development Core Team. R: A language and environment for statistical computing: reference index version 2.8.0. Vienna foundation for statistical computing, 2008. $<$ http:// www.r-project.org.> 11 Jan. 2008

Richards, L. A. Diagnosis and improvement of saline and alkali soils. Washington: United State Salinity Laboratory, 1954. 160p. USDA, Agriculture Handbook, 60.

Silva, A. O.; Soares, T. M.; Silva, E. F. F.; Santos, A. N.; Klar, A. E. Consumo hídrico da rúcula em cultivo hidropônico NFT utilizando rejeitos de dessalinizador em Ibimirim-PE. Irriga, v.17, p.114-125, 2012.

Silva, E. F. F. Anti, G. R.; Carmello, Q. A. C.; Duarte, S. N. Extratores de cápsulas porosas para o monitoramento da condutividade elétrica e do teor de potássio na solução de um solo. Scientia Agrícola, v.57, p.785-789, 2000.

Silva, E. F. F.; Campeche, L. F. S. M.; Duarte, S. N.; Folegatti, M. V. Evapotranspiração, coeficiente de cultivo e de salinidade para o pimentão cultivado em estufa. Magistra, v.17, p.58-63, 2005.

Silva, E. F. F.; Duarte, S. N.; Folegatti, M. V.; Rojais, E. G. Utilização de testes rápidos e extratores de solução do solo na determinação de nitrato e potássio. Engenharia Agrícola, v.23, p.460-467, 2003.

Soares, T. M.; Duarte, S. N.; Silva, E. F. F.; Jorge, C. A. Combinação de águas doce e salobra para produção de alface hidropônica. Revista Brasileira de Engenharia Agrícola e Ambiental, v.14, p.705-714, 2010.

Sousa, A. E. C.; Gheyi, H. R.; Correia, K. G.; Soares, F. A. L.; Nobre, R. G. Crescimento e consumo hídrico de pinhão manso sob estresse salino e doses de fósforo. Revista Ciência Agronômica, v.42, p.310-318, 2011.

Távora, F. J. A. F.; Ferreira, R. G.; Hernandez, F. F. F. Crescimento e relações hídricas em plantas de goiabeira submetidas a estresse salino com $\mathrm{NaCl}$. Revista Brasileira de Fruticultura, v.23, p.441-446, 2001. 